\title{
Thermoplastic polyurethane/(organically modified montmorillonite) nanocomposites produced by in situ polymerization
}

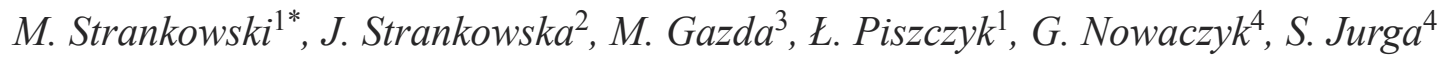 \\ ${ }^{1}$ Gdansk University of Technology, Chemical Faculty, Department of Polymer Technology, G. Narutowicza Str. 11/12, \\ 80-233 Gdansk, Poland \\ ${ }^{2}$ University of Gdansk, Faculty of Mathematics, Physics and Informatics, Department of Applied Physics, Wita Stwosza \\ Str. 57, 80-952 Gdansk, Poland \\ ${ }^{3}$ Gdansk University of Technology, Faculty of Applied Physics and Mathematics, G. Narutowicza Str. 11/12, 80-233 \\ Gdansk, Poland \\ ${ }^{4}$ Adam Mickiewicz University, Faculty of Physics, Department of Macromolecular Physics, Umultowska Str. 85, 61-614 \\ Poznan, Poland
}

\begin{abstract}
A series of polyurethane nanocomposites were synthesized from thermoplastic polyurethanes (with different hard segment ratios) and two types of organically modified montmorillonites (OMMT) - Cloisite ${ }^{\circledR} 10 \mathrm{~A}$ and Cloisite ${ }^{\circledR} 20 \mathrm{~A}$. The thermal behavior was examined by non-isothermal thermogravimetry (TG, DTG), Differential Scanning Calorimetry (DSC) and Dynamic-Mechanical Thermal Analysis (DMTA). The results of X-ray analyses showed that the OMMT produced the intercalated polyurethane nanocomposites. It has been proven that the thermal stability and tensile properties of these new systems were higher when the organoclay was present within the polymer matrix. Moreover, these properties depend on both the OMMT loading and the type of gallery cations of the organically modified montmorillonites.
\end{abstract}

Keywords: nanocomposite, polyurethane, montmorillonite, Cloisite, thermal analysis

\section{Introduction}

The development of materials modified with nanofillers is the basis for producing of many sophisticated products. Presently, several works are being carried out aimed at reducing the dimensions of the existent materials, such as powders or metal oxides and to take advantage of new plastic processing technologies [1-3]. The first works with polymer nanocomposites were carried out during the 1980s by Toyota (polyamide nanocomposites) [4], which started intensive research on these materials and the application of different polymer matrixes: i.a. polyepoxides [5], polyethylene [6], polypropylene [7], polyamide 6 and 11 [8-10], natural rubber [11], polyimides [12] and polystyrene [13, 14]. Currently, research is heavily focused on increasing the scope of polymer nanocomposites, mainly in the electrical [15-17], and automotive industries and in packaging production [18].

Polymer nanocomposites obtained from a polyurethane matrix and the adequate nanofillers offer a chance to produce new materials $[19,20]$, where the least favorable properties of polyurethanes can be improved without compromising their best qualities. Unfortunately, this is very difficult to achieve with common chemical structure modification. The

\footnotetext{
${ }^{*}$ Corresponding author, e-mail: micstran@pg.gda.pl
}

(c) BME-PT 
use of polyurethane nanocomposites is not as extensive as for example polypropylene nanocomposites [21], but interest in them is high because of the enormous opportunities to develop their properties, and thus, opening new opportunities to use these materials in various areas of everyday life and in many industries. Therefore, the probabilities of finding useful applications for polyurethane nanocomposites are very high.

Polymer nanocomposites obtained from natural clays of the montmorillonite type, which consist of layered silicates, have attracted a great deal of attention due to the improvements in the mechanical, thermal, and gas barrier properties of the polymer [22]. Montmorillonite is a natural clay belonging to the $2: 1$ phyllosilicates and its crystal structure is made of two layers of silica tetrahedra sharing some vertexes with an intercalated octahedral sheet of either aluminum or magnesium hydroxide. These silicates self-organize to form stacks with a regular van der Waals gap between the galleries. The existence of ionic bonds (e.g. $\mathrm{Al}^{3+}$ replaced by $\mathrm{Mg}^{2+}$ or $\mathrm{Fe}^{2+}$ generates negative charges that are counterbalanced by cations like $\mathrm{Na}^{+}, \mathrm{Ca}^{2+}$ or $\mathrm{K}^{+}$) and the ability to form hydrogen bonds with water make montmorillonite highly hydrophilic and incompatible with organic polymers [23]. The properties' improvement upon organoclay addition is related to the morphological structure and the dispersion efficiency of the organoclay particles in the polymer matrix, which is associated with the compatibility between the polymer and the organoclay. For this reason, in order to achieve an optimal dispersion of the silicates in the polymer, it is of prime importance to modify the montmorillonite with various organic cationic molecules to render the silicates organophilic [24]. This paper presents the effect of Cloisite 10A [25-29] and Cloisite 20A [30-32] on thermoplastic polyurethane elastomers containing various amounts of stiff segments, and the analysis of the materials obtained carried out using different techniques.

\section{Experimental}

\subsection{Materials}

Montmorillonites modified with a quaternary ammonium salt (OMMT) [Cloisite 10A (organic modifier 2MBHT: dimethyl, benzyl, hydrogenated tallow, quaternary ammonium) and Cloisite 20A (organic modifier 2M2HT: dimethyl, dihydrogenated tallow, quaternary ammonium)] (Southern Clay Products Inc. Texas, USA). The polyester polyol, poly(ethylene, butylene)adipate diol, (PEBA) (Poles 55/20) (ZACHEM, Bydgoszcz, Poland). The 4,4'-methylene diisocyanate (MDI) (Borsodchem, Hungary). 1,4-butanediol (1,4-BD) (BASF, Germany). Organically modified montmorillonites were dried for $6 \mathrm{~h}$ at $90^{\circ} \mathrm{C}$ in a thermal vacuum chamber. PEBA and $1,4 \mathrm{BD}$ were dried separately by heating at $100^{\circ} \mathrm{C}$ and stirring under reduced pressure. MDI was melted at $46^{\circ} \mathrm{C}$ and filtered before use.

\subsection{Nanocomposites preparation}

In the first step, OMMT in an amount of $1 \%$ by weight was dispersed in PEBA by means of a homogenizer (5000 r.p.m., $80^{\circ} \mathrm{C}, 5 \mathrm{~h}$ ) and an ultrasound bath. In the second step, a calculated amount of MDI was added to the obtained dispersion and the mixture was stirred at $80^{\circ} \mathrm{C}$ for 1 hour to obtain a prepolymer. In the third step the prepolymer was mixed with vigorous stirring with $1,4 \mathrm{BD}$ at a $1.05 \mathrm{NCO} /$ $\mathrm{OH}$ molar ratio and poured into a heated $\left(90^{\circ} \mathrm{C}\right)$ centrifuge drum. After the solidification (30 min) the resulting $2 \mathrm{~mm}$ thick band was annealed at $100^{\circ} \mathrm{C}$ for 6 hours to complete the reaction. Two types of non-modified polyurethanes were obtained, with different amounts of hard segments (TPUh $46 \% \mathrm{HS}$ and TPUs - $30 \% \mathrm{HS}$ ).

\subsection{Nanocomposites characterization}

Thermal analysis (TG and DTG curves) was performed using a Perkin-Elmer Thermogravimetric Analyzer TGA Pyris 1 at a heating rate of $20^{\circ} \mathrm{C} \cdot \mathrm{min}^{-1}$ under nitrogen flow and heating program 25$600^{\circ} \mathrm{C}$. DSC measurements were made using a Perkin-Elmer Differential Scanning Calorimeter DSC 7 for encapsulated (aluminum pans) samples of ca. 3-10 $\mathrm{mg}$ at a heating/cooling rate of $20^{\circ} \mathrm{C} \cdot \mathrm{min}^{-1}$ under nitrogen flow. A second melting scan was also performed. The calibration of the temperature and heat flow scales at the same heating rate was performed with In and Zn. For the DMTA measurements an analyzer from Polymer Laboratories was used in bending mode (dual cantilever) (heating form -70 to $120^{\circ} \mathrm{C}$ at $10 \mathrm{~Hz}$ frequency and $4^{\circ} \mathrm{C} \cdot \mathrm{min}^{-1}$ heating rate). The $\mathrm{X}$-ray patterns of the crystalline residues were recorded in an $X^{\prime}$ Pert Philips diffractometer (source radiation: $\mathrm{CuK}_{\alpha 1}, \lambda=0.1546 \mathrm{~nm}$, 
$40 \mathrm{kV}, 30 \mathrm{~mA})$ in the $0.5-10^{\circ}(2 \theta$ range $)$ and at scanning rate $0.25^{\circ} \cdot \mathrm{s}^{-1}$. A Zwick/Roell Z020 testing machine was used to verify the mechanical properties of the samples (ISO 527, tension mode, speed $\left.300 \mathrm{~mm} \cdot \mathrm{min}^{-1}\right)$.

\section{Results and discussion}

\subsection{Differential scanning calorimetry (DSC)}

The thermal behavior of polyurethane nanocomposites and unmodified TPU was analyzed during a controlled temperature increase. For a system containing a low amount of rigid segments (TPUs), it was observed that the polyurethane nanocomposites melting temperature increased in comparison with its pure reference material (Figure 1a). For TPUs containing $1 \%$ of Cloisite $10 \mathrm{~A}$ the melting temperature increases $2.7^{\circ} \mathrm{C}$, whereas for the sample containing 1\% Cloisite 20A the maximal melting rate of crystallites was observed to be $6^{\circ} \mathrm{C}$ higher than the melting temperature of the unmodified system. The enthalpy values of the transitions for the investigated systems containing nanofiller particles, connected with the melting process of the crystalline aggregates, are lower than those of pure polyurethanes (Table 1). The lowest value of transition enthalpy was observed for the nanocomposite with $1 \%$ Cloisite 20A [TPUs(20A)]. The decrease in transition heat could be brought about by the interaction of the nanofiller plates with the rigid polyurethane segments, which makes the packing of these domains difficult. Thus, as a consequence of the presence of plates in the nanocomposite structure, the crystallization rate of the modified systems decreases.

For polyurethanes containing a higher fraction of rigid segments (TPUh) and nanofiller particles, an increase of the melting point temperature was observed (Figure 1b). For TPUh(10A) the melting temperature increases $1.6^{\circ} \mathrm{C}$ in comparison with pure TPUh, whereas for the TPUh(20A) sample the temperature difference referred to the pure reference material was equal to $5.6^{\circ} \mathrm{C}$. An interesting fact is that the transition enthalpy for nanocomposites containing $1 \%$ Cloisite $10 \mathrm{~A}$ is about $1.7 \mathrm{~J} / \mathrm{g}$ higher compared to TPUh, while for the system containing the second nanofiller, TPUh(20A) - the enthalpy value decreases at about $3.9 \mathrm{~J} / \mathrm{g}$ (Table 1). Most probably, nanofiller Cloisite 10A, having a major chemical affinity towards polyurethane chains, can increase the density of the nucleation process and, as a consequence, a higher value of crystallization enthalpy for TPUh(10A) is observed. It is significant fact is that polyurethanes containing a higher amount of rigid segments also possess higher transition enthalpies.

Polyurethane nanocomposites prepared using the organically modified montmorillonite Cloisite 20A, are characterized by higher melting temperatures compared to systems containing Cloisite 10A.

Table 1. The melting endothermic parameters estimated base on DSC measurements for polyurethane nanocomposites and pure TPU

\begin{tabular}{|l|c|c|}
\hline \multicolumn{1}{|c|}{ Sample } & $\begin{array}{c}\text { Melting temperature (max.) } \\
{\left[{ }^{\circ} \mathbf{C}\right]}\end{array}$ & $\begin{array}{c}\text { Enthalpy }(\mathbf{\Delta H}) \\
{\left[\mathbf{J}^{\mathbf{0}} \mathbf{g}^{-\mathbf{1}}\right]}\end{array}$ \\
\hline TPUh & 163.6 & 16.3 \\
\hline TPUh(10A) & 165.2 & 18.1 \\
\hline TPUh(20A) & 169.2 & 12.4 \\
\hline TPUs & 153.7 & 7.7 \\
\hline TPUs(10A) & 156.0 & 6.7 \\
\hline TPUs(20A) & 159.7 & 5.6 \\
\hline
\end{tabular}

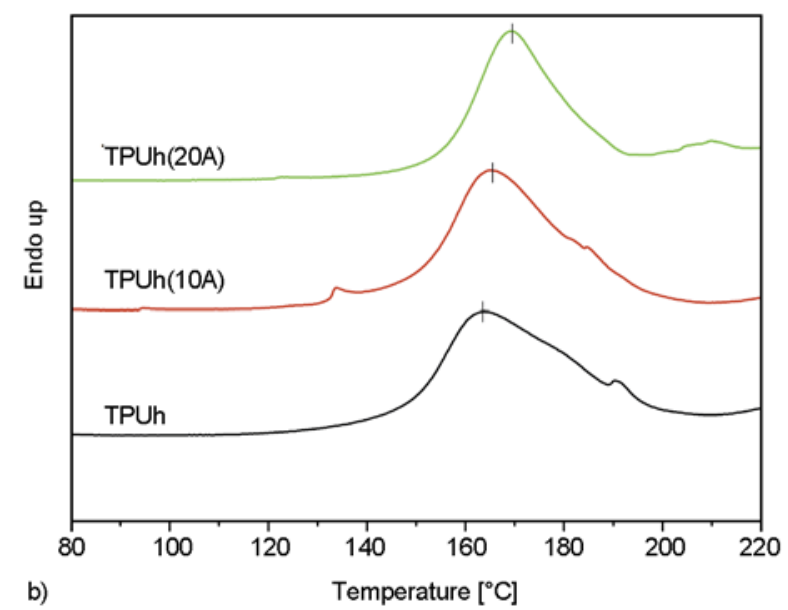

b)

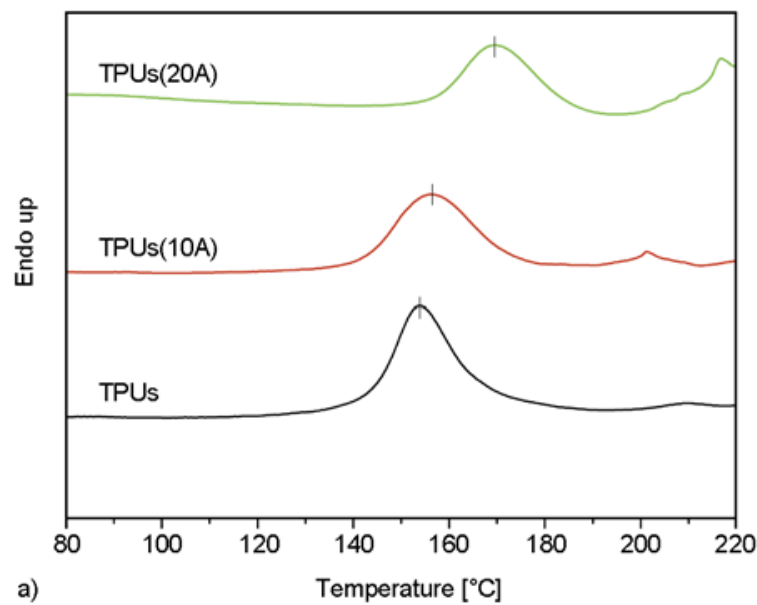

Figure 1. DSC curves for polyurethane nanocomposites and pure TPU 


\subsection{Dynamic mechanical thermal analysis (DMTA)}

The dynamic mechanical thermal analysis of the mechanical properties enabled the estimation of the glass transition temperatures of polyurethanes and systems modified by nanoparticles. Meaningful changes were registered for the storage modulus, which reached higher values in the modified systems, especially in the temperature range above glass transition. The highest value of the storage modulus, at room temperature, was registered for the nanocomposite containing 1\% Cloisite 20A (Figure 2a). It was also observed that the addition of both nanofillers caused the stiffening of the more elastic polymer matrix (containing a lower amount of rigid segments).

For systems containing a higher amount of rigid segments in the polymer matrix, the shifting of the loss tangent to lower temperatures $\left(3.6^{\circ} \mathrm{C}\right.$ less than the unmodified polyurethane) was observed (Figure $2 b$ ). For the TPUh (10A) system it was registered that the value of the storage modulus is higher compared to TPUh in the studied temperature range (Table 2). Addition of the second nanofiller (Cloisite 20A) to a more rigid polyurethane matrix did not produce a meaningful increase of the stor-

Table 2. List of temperatures corresponding to the maximum peaks of the $\tan \delta(T)$ curves and storage modulus in $-30,0,30^{\circ} \mathrm{C}$ temperatures

\begin{tabular}{|l|c|c|c|c|}
\hline \multirow{2}{*}{ Sample } & \multicolumn{3}{|c|}{ Storage module $\mathbf{E}^{\prime}[\log \mathbf{P a}]$} & $\mathbf{T}_{\max }(\mathbf{t a n} \boldsymbol{\delta})$ \\
\cline { 2 - 4 } & $-\mathbf{3 0}^{\circ} \mathbf{C}$ & $\mathbf{0}^{\circ} \mathbf{C}$ & $\mathbf{3 0}^{\circ} \mathbf{C}$ & $\left.{ }^{\circ} \mathbf{C}\right]$ \\
\hline TPUh & 8.6 & 8.2 & 7.8 & -2.0 \\
\hline TPUh(10A) & 8.8 & 8.4 & 8.1 & -5.6 \\
\hline TPUh(20A) & 8.7 & 8.2 & 7.9 & -2.0 \\
\hline TPUs & 8.8 & 7.5 & 7.2 & -6.5 \\
\hline TPUs(10A) & 8.8 & 7.9 & 7.5 & -5.3 \\
\hline TPUs(20A) & 8.8 & 8.1 & 8.0 & -8.3 \\
\hline
\end{tabular}

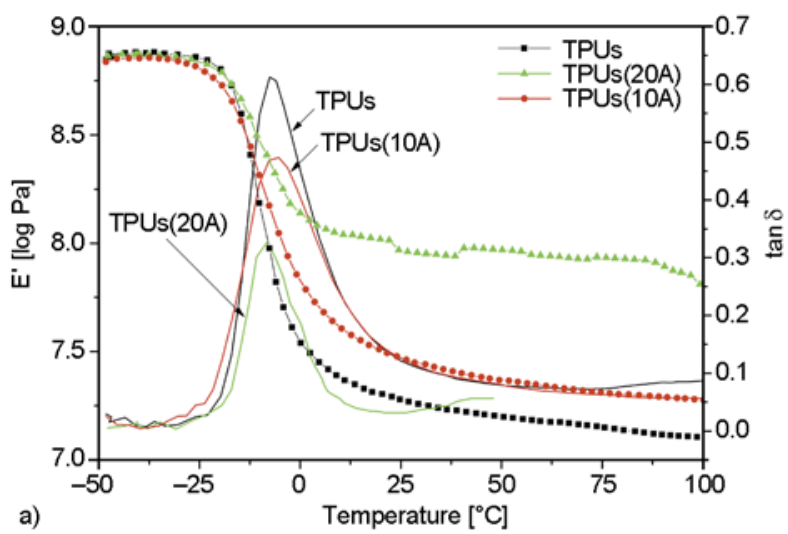

age modulus in the investigated temperature range (Figure 2b). This effect could demonstrate the significant interaction of incorporated nanofillers with the polyurethane phase.

Relatively small amounts of nanofillers incorporated to the polymer matrix caused a distinct increase of the storage modulus values for the modified systems. It should likewise be stressed that systems containing a lower amount of rigid segments in the polymer matrix are more susceptible to interaction, thus the reinforcement effect in these systems is more visible.

\subsection{Rheological properties (ARES)}

The rheology of polyurethane nanocomposites containing Cloisite $10 \mathrm{~A}$ or Cloisite 20A was examined in order to obtain information about the influence of nanoparticles on the rheological behavior of polymer alloys. The systems were measured at $200^{\circ} \mathrm{C}$ and $0.1 \div 100 \mathrm{rad} / \mathrm{s}$ frequency range. Nanofiller plates in the systems containing either more (TPUh) or less rigid segments (TPUs) caused an increase of the viscosity of the obtained nanocomposites. For the TPUh(10A) system the highest dynamic viscosity was registered, in comparison to nanocomposites TPUh(20A) obtained using another nanofiller. The opposite behavior was measured for two systems with the lowest amount of rigid segments, where higher viscosity was registered for the TPUs(20A) system. Additionally, TPUs nanocomposites and its TPUs equivalents had higher viscosity values, compared to the values registered for nanocomposites with a more rigid polyurethane matrix and their pure equivalent (TPUh) (Figure 3). The dynamic storage modulus $\left(G^{\prime}\right)$ as a frequency function for studied systems has a close characteristic through the whole frequency range (Figure 4a, b). The highest storage modulus values were regis-

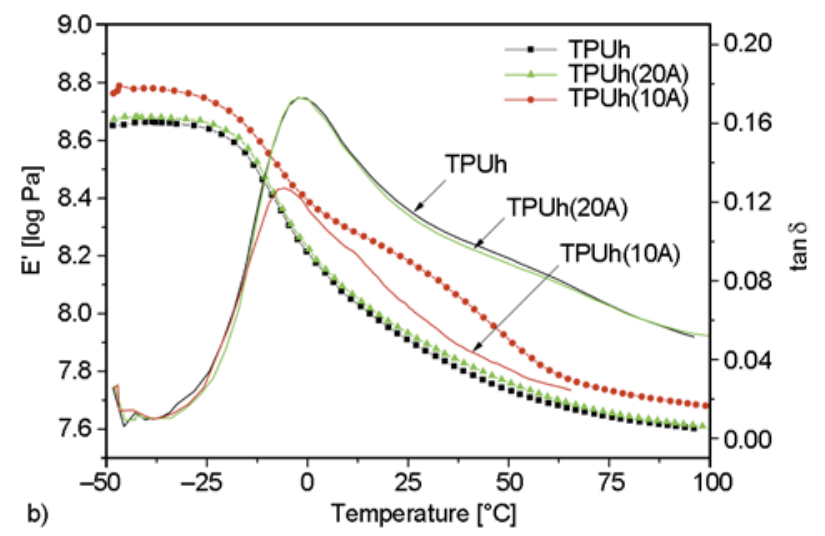

Figure 2. Temperature dependences of dynamic storage modulus $\left(E^{\prime}\right)$, loss tangent $(\tan \delta)$ for nanocomposites and TPU 

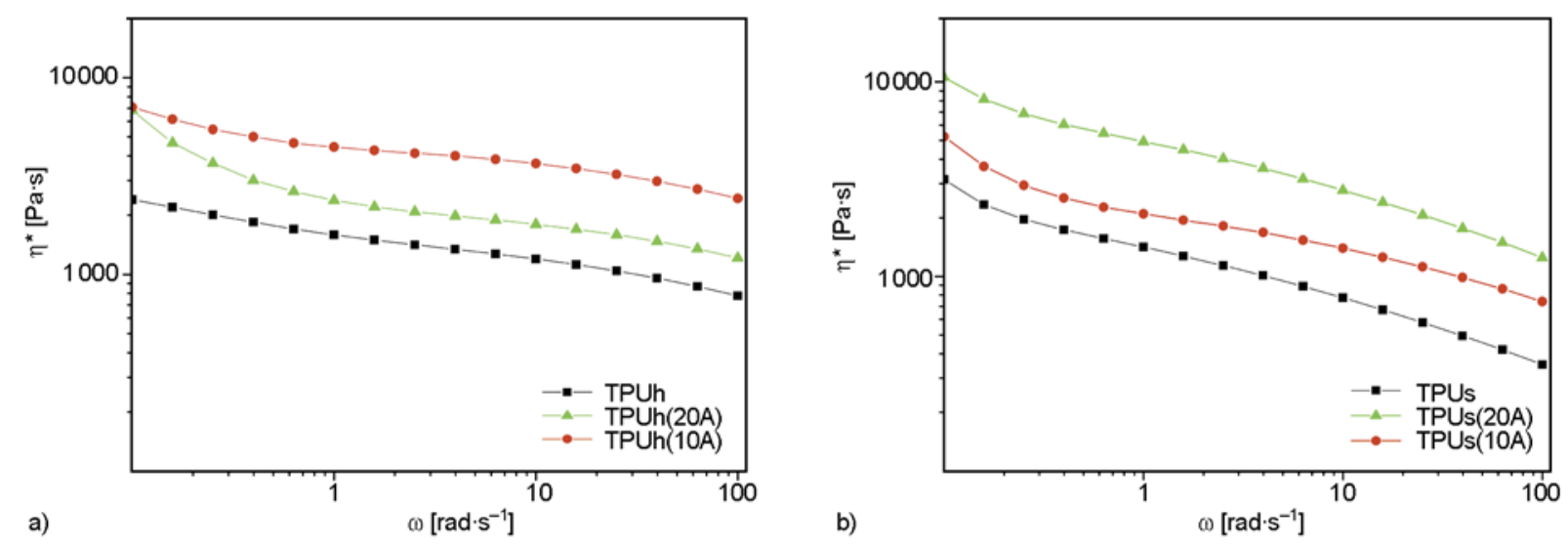

Figure 3. Dynamic viscosity $\left(\eta^{*}\right)$ dependence on frequency $(\omega)$ for TPUh, TPUs and nanocomposites
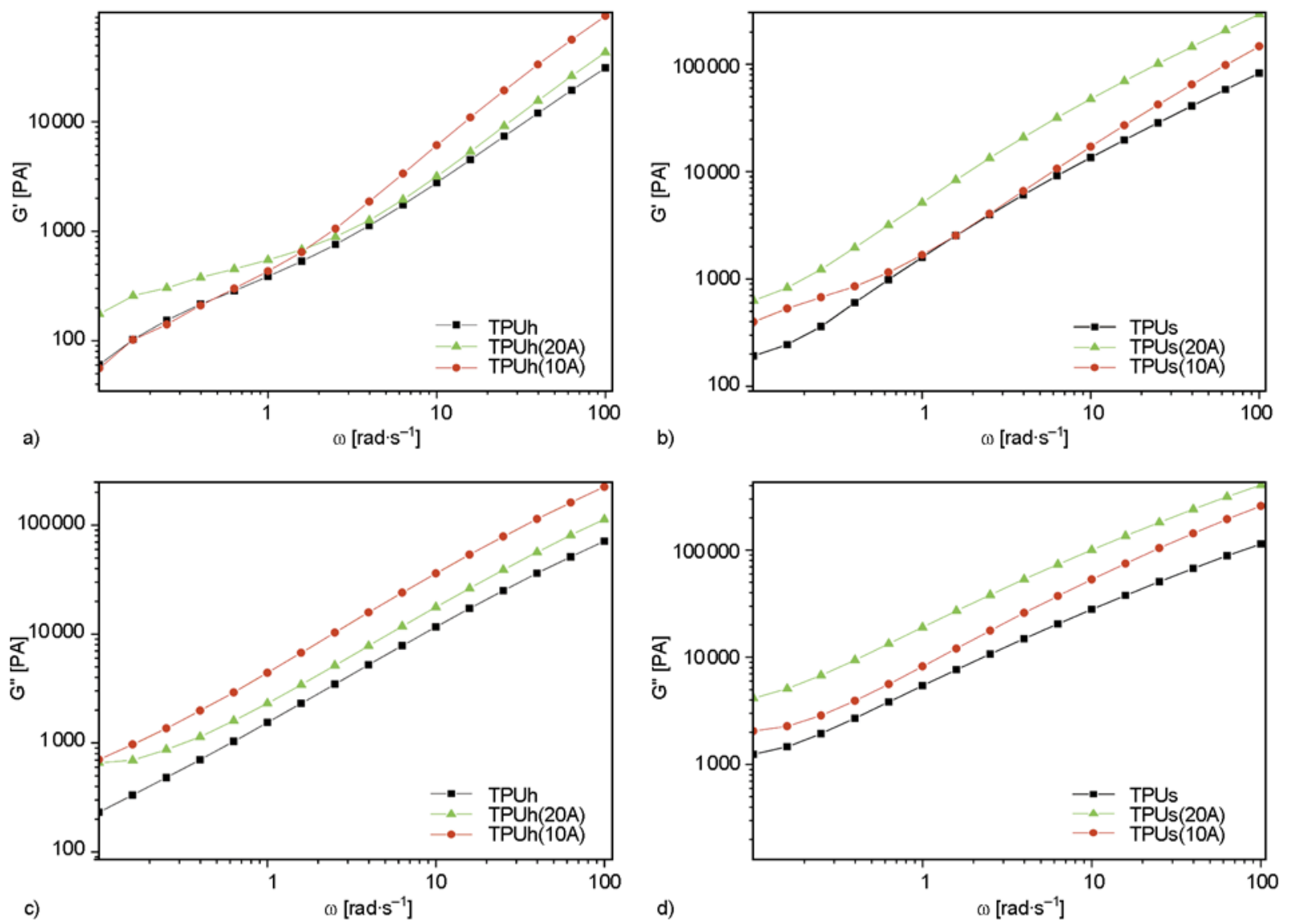

Figure 4. Dynamic loss modulus $\left(G^{\prime}\right)$ as a function of the frequency ( $\omega$ ) for TPUh (a), TPUs (b), and nanocomposites. Dynamic loss modulus $\left(G^{\prime \prime}\right)$ as a function of frequency $(\omega)$ for TPUh (c), TPUs (d) and nanocomposites.

tered for the TPUs(20A) system. Furthermore, the $G^{\prime}$ modulus for TPUs, TPUs(10A) and TPUs(20A) systems were higher than for TPUh, TPUh(10A) and TPUh(20A).

For polyurethane nanocomposites obtained using Cloisite 10A and Cloisite 20A, the dynamic loss modulus $\left(G^{\prime \prime}\right)$ as a function of the frequency had higher values in comparison with $G^{\prime \prime}$ for their pure equivalents (TPUh and TPUs) (Figure 4c, d). The highest values of $G^{\prime \prime}$ were registered for $\operatorname{TPUh}(20 \mathrm{~A})$ and TPUs(10A). Furthermore, TPUs nanocomposites and unmodified TPUs had higher loss moduli through the whole frequency range had higher loss moduli in comparison with their more rigid equivalents TPUh.

\subsection{Thermogravimetric analysis (TGA)}

Thermogravimetric analysis is one of the most important methods used to study polymer nanocom- 
posites. The results of these experiments make the description of the nanofiller influence on the improvement rate of polymer thermal properties possible. Nonetheless, even for commercial nanocomposites, it is possible to find results of studies that indicate the absence of thermal improvement for modified polymers. The fact is that the preparation of nanocomposites with better thermal parameters than the initial materials is difficult. For all samples the weight losses for the first and second stages were observed (Figure 5b, 6b). The first weight loss during thermal degradation of TPU's is due to the degradation of the hard segment as a consequence of the relatively low thermal stability of the urethane groups whereas the second weight loss has been associated to soft segment decomposition [33]. According to the analysis of the results obtained for nanocomposite systems containing lower amounts of rigid segments in the polyurethane matrix (Figure 5 and 6) a clear improvement of the thermal parameters is visible. Temperatures, at which $95 \%$ of the initial mass of the sample remained, are higher for nanocomposites TPUs(10A) and TPUs(20A) than for the unmodified systems - differences of 9.3 and $13.6{ }^{\circ} \mathrm{C}$, respectively (Table 3). Especially obvious is the shifting of the $\mathrm{d} P_{\mathrm{zm}} / \mathrm{d} T$ curve maximum. For TPUs(10A) and TPUs(20A) a shift of about $22.8^{\circ} \mathrm{C}$ towards higher temperatures can be noticed, which indicates a considerable improvement of thermal strength in nanocomposite systems (Table 3). The addition of Cloisite 10A and Cloisite 20A in considerable quantities improves the thermal strength of polyurethane elastomers containing a lower amount of rigid segments in the polymer matrix. The analysis of the maxima on the derivative curve of $\%$ mass conservation as a function of temperature indicates the distinct increase of thermal stability obtained at the $350 \div 450^{\circ} \mathrm{C}$ temperature range.

For polyurethane systems containing a higher share of rigid segments - TPUh(10A) and TPUh(20A) - a considerable improvement of thermal stability was
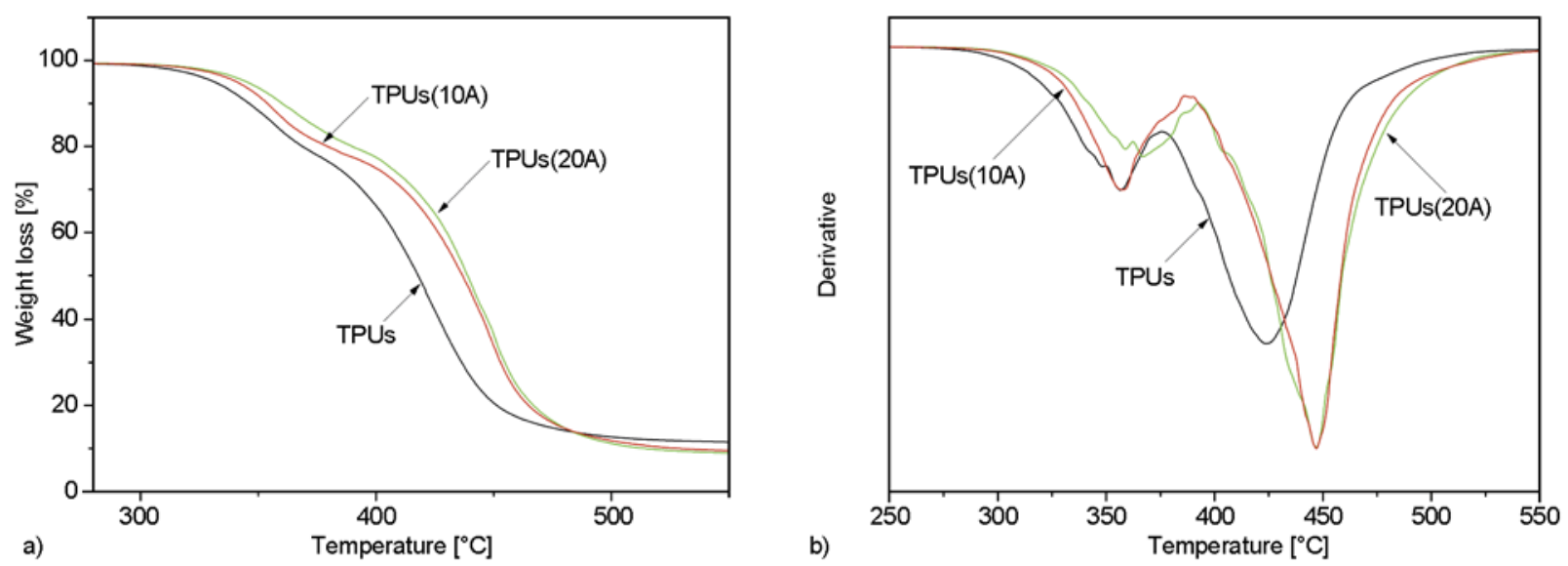

Figure 5. \% mass conservation and derivative dependence on temperature for TPUs and TPUs nanocomposites
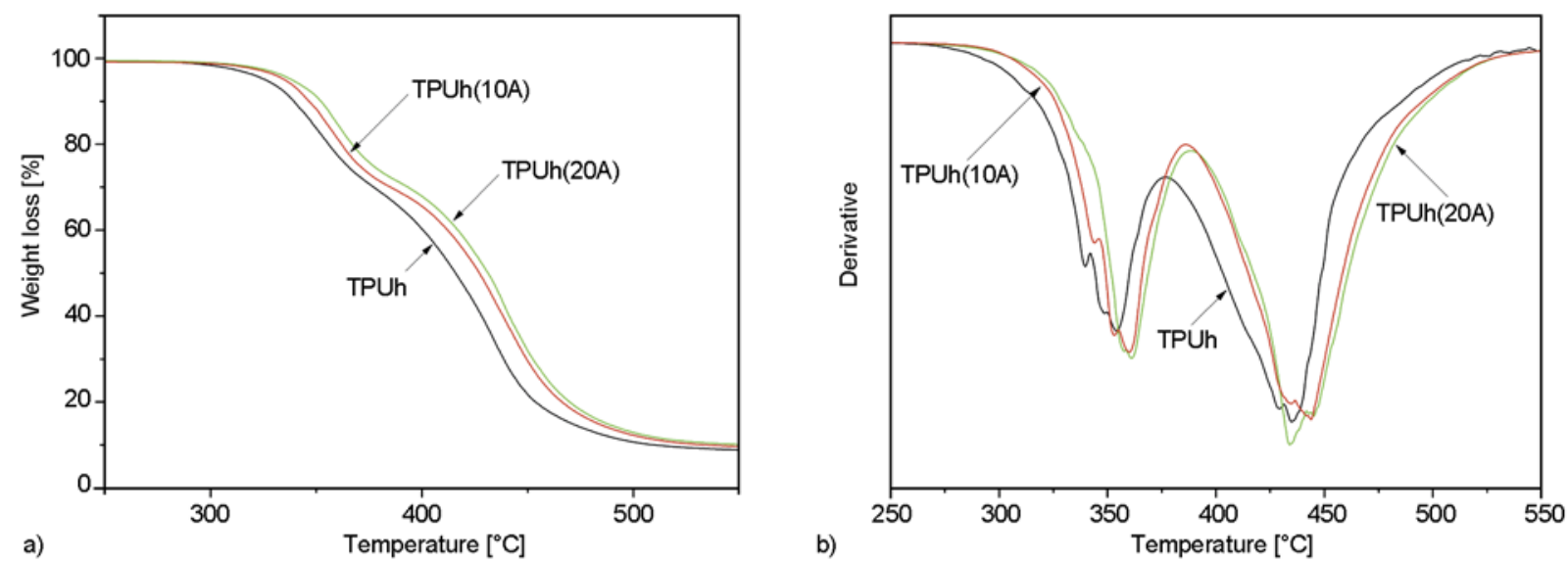

Figure 6. \% mass conservation and derivative dependence on temperature for TPUh and TPUh nanocomposites 
Table 3. Thermal decomposition of pure TPU and TPU nanocomposites

\begin{tabular}{|l|c|c|c|}
\hline \multirow{3}{*}{ Sample } & \multicolumn{2}{|c|}{ Weight loss } & \multirow{2}{*}{ T $_{\max }$} \\
\cline { 2 - 3 } & $\mathbf{5 \%}$ & $\mathbf{5 0 \%}$ & \multirow{2}{*}[{}^{\circ}\mathbf{C}]{} \\
\cline { 2 - 3 } & \multicolumn{2}{|c|}{ Temperature $\left[{ }^{\circ} \mathbf{C}\right]$} & $356.3 ; 424.1$ \\
\hline TPUs & 331.4 & 417.8 & $357.5 ; 446.9$ \\
\hline TPUs(10A) & 340.7 & 436.6 & $366.8 ; 446.7$ \\
\hline TPUs(20A) & 345.0 & 438.7 & $36.0 ; 435.0$ \\
\hline TPUh & 325.8 & 415.5 & $354.0 ;$ \\
\hline TPUh(10A) & 335.1 & 427.2 & $360.1 ; 444.0$ \\
\hline TPUh $(20 \mathrm{~A})$ & 338.2 & 431.3 & $361.0 ; 434.2$ \\
\hline
\end{tabular}

also registered. It is worth noticing that the improvements in thermal stability are visible especially in the early stage of the sample decomposition to gaseous products. $5 \%$ mass loss for TPUh(10A) system is observed at $335.1^{\circ} \mathrm{C}$ temperature, $9.3^{\circ} \mathrm{C}$ higher than for the TPUh sample. For the TPUh(20A) nanocomposite, the shifting of the temperature at which a $5 \%$ mass is lost was recorded to be $12.4^{\circ} \mathrm{C}$ higher compared to the unmodified system. In the case of nanocomposites with rigid segments, the distinct improvement of thermal stability within flexible segments was not observed. It is noticeable, however, a difference in thermal stability, especially in an early stage of decomposition, between TPUs and TPUh systems. It is related to a lower amount of thermally weaker urethane bond occurring in the TPUs sample, which causes a higher thermal resistance in this type of system. Comparing the different nanofillers applied to the modification of polyurethane, it was noticed that, regarding thermal stability, it seems to be favorable to use Cloisite 20A. Nonetheless, both nanoclays used to prepare the polyurethane systems produced the desired effect on the thermal properties of the obtained products.

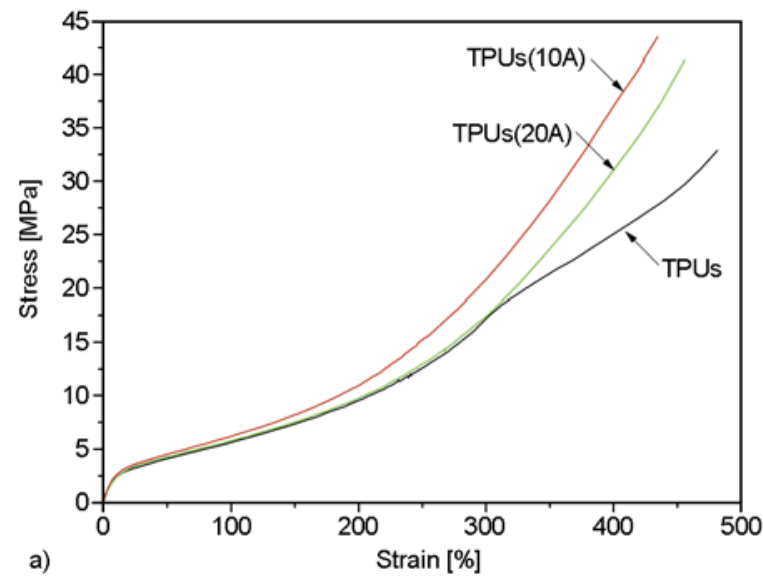

\subsection{Mechanical properties}

For all the prepared nanocomposite systems strength experiments were performed. The most distinct reinforcement effect of nanofiller particles was observed in their extension measurements. For a more elastic polyurethane matrix, containing $1 \%$ Cloisite 10A - TPUs(10A), an improvement of the stress at break of up to $10 \mathrm{MPa}$ compared to the unmodified polyurethane was obtained (Table 4). When the second nanofiller (Cloisite 20A) was added to a system containing a lower amount of rigid segments, the stress at break was equal to 41.2 $\mathrm{MPa}$ (Table 4). This value is $8 \mathrm{MPa}$ higher than that for pure thermoplastic polyurethane (TPUs). With the increase of the stress needed to break the samples, a relative elongation at breakincrease of the elongation at break was not observed. TPUs(10A) and TPUs(20A) reveal negligibly lower values for the maximal relative elongation at break (Figure 7a). This means that the nanofillers influence on the polyurethane matrix results in it stiffening. In a system containing a higher amount of rigid segments, an improvement of the mechanical properties of the samples was also observed as a consequence of organoclay addition. The highest value of stress at break was registered for the TPUh(10A) sample and equals to 46.7, 14.1 MPa higher than for the TPUh system without a nanofiller (Table 4, Figure $7 \mathrm{~b}$ ). Compared to the pure polyurethane, the stress at break for TPUh(20A) containing Cloisite 20A increases up to $11.2 \mathrm{MPa}$ (Table 4). Polyurethanes modified by nanofillers, with a higher amount of rigid segments, exhibit a lower relative elongation at break in comparison with their pure reference materials.

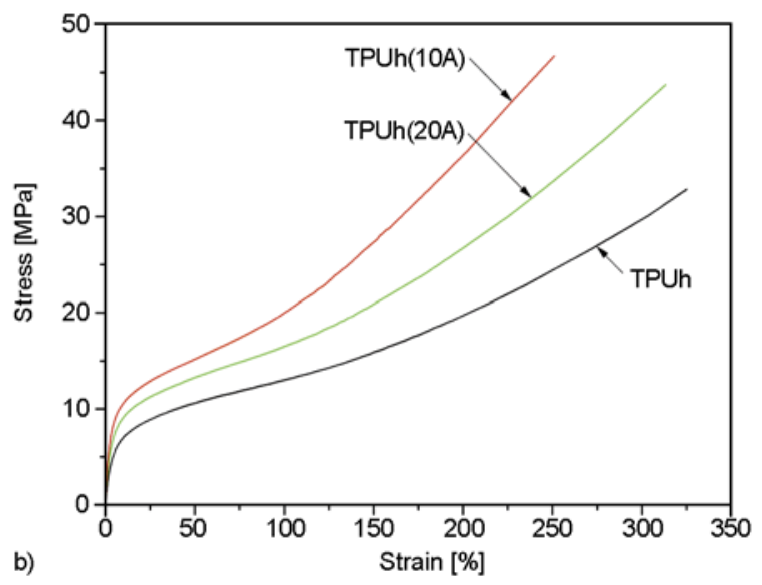

Figure 7. Stress dependence on relative extension during elongation for TPU and TPU nanocomposites 
Table 4. List of stress at break and relative extension during elongation for TPU and TPU nanocomposites

\begin{tabular}{|l|c|c|}
\hline \multicolumn{1}{|c|}{ Sample } & Max. Stress [MPa] & Max. Strain [\%] \\
\hline TPUh & 32.6 & 325 \\
\hline TPUh(10A) & 46.7 & 251 \\
\hline TPUh(20A) & 43.8 & 313 \\
\hline TPUs & 33.2 & 481 \\
\hline TPUs(10A) & 43.5 & 436 \\
\hline TPUs(20A) & 41.2 & 455 \\
\hline
\end{tabular}

Therefore, the addition of nanofiller particles to thermoplastic polyurethanes caused an increase in the intensity of the stress needed to break the sample and a negligible decrease of the maximal relative elongation at break. A greater improvement in strength properties is observed when the Cloisite $10 \mathrm{~A}$ nanofiller is added to the polyurethane matrix (Figure $7 \mathrm{a}, \mathrm{b})$. It can be caused by a higher compatibility of this nanofiller towards polyurethane chains. Also, the dispersion rate of the particles very sensitively influences the mechanical properties of the polyurethane nanocomposites, and, related with this, the functional features of the materials obtained.

\subsection{X-ray diffraction (XRD)}

The X-ray diffraction method is able to describe the degree of nanofiller intercalation between polymer chains and to indicate what kind of dispersive system was obtained. The diffraction spectra of Cloisite 10A and Cloisite 20A made an estimation of the nanocomposite interlayer distances possible (Table 5). Pure, unmodified montmorillonite (MMT) has a diffractive maximum at $2 \theta=6.8^{\circ}$ which belongs to a distance between galleries equal to $1.28 \mathrm{~nm}$. Organically modified montmorillonites (Cloisite 10A and Cloisite 20A) have therefore much wider galleries compared with pure MMT. The increase of interlayer spaces allows polymer chains to penetrate more easily into the nanofiller plates. Pure polyurethanes in the $2 \theta=1 \div 10^{\circ}$ angle range have no diffractive maxima (Figure $8 a, b$ ). Therefore, the degree of semicrystallinity of the obtained polyurethane elastomers is difficult to estimate using diffractive methods. On that, the XRD analysis points to amorphous polyurethane systems. For TPUs(10A), a distinct diffractive maximum shifting towards lower angles is observed, which means that the interlayer space between the MMT plates increases from $1.86 \mathrm{~nm}$ to $3.32 \mathrm{~nm}$ (Figure 8a). The TPUh(10A) nanocomposite, characterized by a more rigid polymer matrix and containing Cloisite $10 \mathrm{~A}$, presents a diffractive maximum at $2 \theta=2.75^{\circ}$. It belongs to a broadening of the nanoclay galleries to about $1.35 \mathrm{~nm}$. Additionally, for this sample, the decrease of the diffractive maximum intensity was observed. This is probably related to the partial exfoliation process of the nanofiller in the polyurethane matrix. In the X-ray spectra of nanocomposites with Cloisite $10 \mathrm{~A}$ a second, less intensive, diffractive maximum also occurs at $2 \theta \approx 5.2^{\circ}$, which is connected with the next diffraction order $-\mathrm{d}(002)$. For TPUs(20A) obtained using the second nanofiller, which was in this case incorporated to a more elastic polyurethane matrix, a diffractive maximum shifting $\mathrm{d}(001)$ from 2.48 to $3.46^{\circ}$ was observed (Table 5, Figure $8 \mathrm{~b}$ ). A similar $2 \theta$ angle value was estimated for $\operatorname{TPUh}(20 \mathrm{~A})$ - the interlayer space in this sample increases to $3.57 \mathrm{~nm}$. Cloisite 20A maxima ( $2 \theta=$ $3.6^{\circ}$ ) presents a higher intensity than nanocomposites obtained from the second type of nanofiller. In this case, it seems that the polyurethane chains pene-

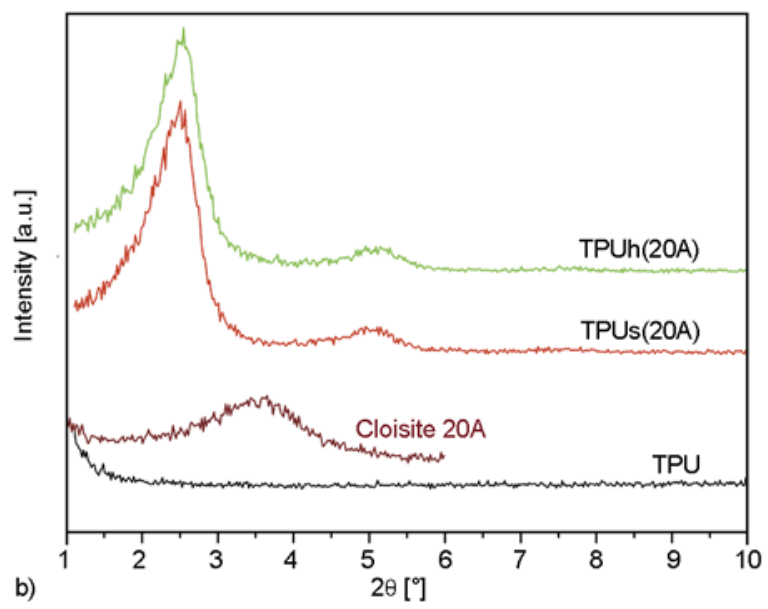

a)

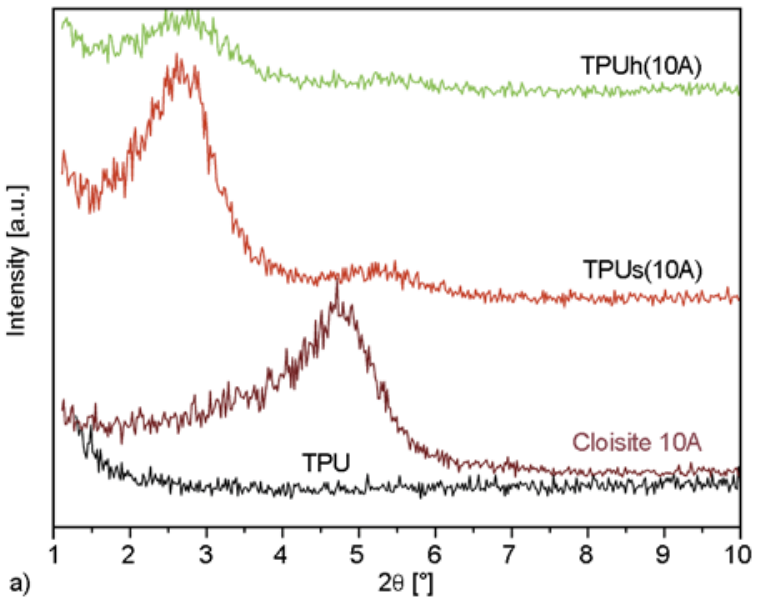

Figure 8. X-ray spectra of polyurethane nanocomposites and its pure reference materials 
Table 5. List of diffractive maxima and interlayer spacer for TPU nanocomposites and TPU

\begin{tabular}{|l|c|c|}
\hline \multicolumn{1}{|c|}{ Sample } & $\mathbf{2 \theta}\left[^{\circ}{ }^{\circ}\right.$ & $\mathbf{d}_{\mathbf{0 0 1}}[\mathbf{n m}]$ \\
\hline TPUh & - & - \\
\hline TPUh(10A) & 2.75 & 3.21 \\
\hline TPUh(20A) & 2.47 & 3.57 \\
\hline TPUs & - & - \\
\hline TPUs(10A) & 2.66 & 3.32 \\
\hline TPUs(20A) & 2.55 & 3.46 \\
\hline Cloisite 10A & 4.76 & 1.86 \\
\hline Cloisite 20A & 3.56 & 2.48 \\
\hline
\end{tabular}

trate the Cloisite 10A nanofiller plates to a more considerable degree. This is related to the higher interlayer spaces observed for this kind of nanoclay. According to the X-ray spectra of the polyurethanes modified by nanofillers, the resulting nanocomposites present an intercalated structure.

\section{Conclusions}

Polyurethane/OMMT nanocomposites were prepared by a two-step process using MDI, 1,4-BD, Polyol and modified MMT. The effect of the addition of $1 \%$ nanofiller (Cloisite 10A and Cloisite 20A) over the polyurethane matrix containing a different quantity of stiff segments was studied. The DSC results showed a slight increase of the melting temperature with Cloisite loading. For nanocomposites with a more elastic polyurethane matrix (TPUs), it was observed that the addition of organically modified aluminosilicates affected the rubbery region of the systems. The study of the mechanical strength shows a clear increase of this parameter after the application of a nanofiller to the polyurethane matrix. In the best case, a $43 \%$ higher stress at break was attained for TPUh(10A) respect to the mechanical resistance of TPUh. The systems containing nanofillers were observed to possess a higher viscosity compared to their unmodified equivalents. In part, this is an indicator of the degree of dispersion and the interaction of the nanofiller particles in the polyurethane matrix. The study of the thermal stability confirmed that the nanocomposites are thermally more stable than the unmodified systems. A non-significant better thermal stability was observed when the nanofiller Cloisite 20A was used. The Xray analysis indicated exfoliation (for the Cloisite 10A nanoclay) and an intercalated structure in the nanocomposites containing Cloisite 20A. The obtained results confirm a higher compatibility of Cloisite 10A with the polyurethane matrix in comparison with the other nanofiller introduced.

\section{References}

[1] Azizi H., Morshedian J., Barikani M., Wagner M. H.: Effect of layered silicate nanoclay on the properties of silane crosslinked linear low-density polyethylene (LLDPE). Express Polymer Letters, 4, 252-262 (2010). DOI: $10.3144 /$ expresspolymlett.2010.32

[2] Tyurin A., De Filpo G., Cupelli D., Nicoletta F. P., Mashin A., Chidichimo G.: Particle size tuning in silver-polyacrylonitrile nanocomposites. Express Polymer Letters, 4, 71-78 (2010).

DOI: 10.3144 /expresspolymlett.2010.12

[3] Samal S. K., Mohanty S., Nayak S. K.: Thermal, morphological and dynamic mechanical characterization of melt blended PC nanocomposites. Advanced Materials Research, 29-30, 275-278 (2007).

DOI: 10.4028/www.scientific.net/AMR.29-30.275

[4] Bieliński D., Rajkiewicz M., Mikołajska A., Majewski K.: Polymer nanocomposites - Selected domains of application (in Polish). Elastomery, 11, 18-24 (2007).

[5] Yasmin A., Abot J. L., Daniel I. M.: Processing of clay/epoxy nanocomposites by shear mixing. Scripta Materialia, 49, 81-86 (2003).

DOI: $10.1016 / \mathrm{S} 1359-6462(03) 00173-8$

[6] Kim Y. C.: Effect of maleated polyethylene on the crystallization behavior of LLDPE/clay nanocomposites. Polymer Journal, 38, 250-257 (2006). DOI: $10.1295 /$ polymj. 38.250

[7] García-López D., Picazo O., Merino J. C., Pastor J. M.: Polypropylene-clay nanocomposites: Effect of compatibilizing agents on clay dispersion. European Polymer Journal, 39, 945-950 (2003).

DOI: $10.1016 / \mathrm{S} 0014-3057(02) 00333-6$

[8] Yano K., Usuki A., Okada A., Kurauchi T., Kamigaito O.: Synthesis and properties of polyimide-clay hybrid. Journal of Polymer Science Part A: Polymer Chemistry, 31, 2493-2498 (1993).

DOI: $10.1002 /$ pola.1993.080311009

[9] Hagesawa N., Okamoto H., Kato M., Usuki A., Sato N.: Nylon 6/Na-montmorillonite nanocomposites prepared by compounding Nylon 6 with $\mathrm{Na}$-montmorillonite slurry. Polymer, 44, 2933-2937 (2003).

DOI: $10.1016 / \mathrm{S} 0032-3861(03) 00215-5$

[10] Zhou Q., Wang K., Loo L. S.: Abrasion studies of nylon 6/montmorillonite nanocomposites using scanning electron microscopy, fourier transform infrared spectroscopy, and X-ray photoelectron spectroscopy. Journal of Applied Polymer Science, 113, 3286-3293 (2009). DOI: $10.1002 / a p p .30229$

[11] Varghese S., Karger-Kocsis J.: Natural rubber-based nanocomposites by latex compounding with layered silicates. Polymer, 44, 4921-4927 (2003). DOI: 10.1016/S0032-3861(03)00480-4 
[12] Delozier D. M., Orwoll R. A., Cahoon J. F., Johnston N. J., Smith Jr. J. G., Conell J. W.: Preparation and characterization of polyimide/organoclay nanocomposites. Polymer, 43, 813-822 (2002).

DOI: $10.1016 / \mathrm{S} 0032-3861(01) 00640-1$

[13] Fu X., Qutubuddin S.: Polymer-clay nanocomposites: Exfoliation of organophilic montmorillonite nanolayers in polystyrene. Polymer, 42, 807-813 (2001). DOI: $10.1016 / \mathrm{S} 0032-3861(00) 00385-2$

[14] Ma C-C. M., Chen Y-J., Kuan H-C.: Polystyrene nanocomposite materials: Preparation, morphology, and mechanical, electrical, and thermal properties. Journal of Applied Polymer Science, 98, 2266-2273 (2005). DOI: $10.1002 /$ app.22121

[15] Jones W. E. Jr., Chiguma J., Johnson E., Pachamuthu A., Santos D.: Electrically and thermally conducting nanocomposites for electronic applications. Materials, 3, 1478-1496 (2010). DOI: $10.3390 / \mathrm{ma} 3021478$

[16] Tomer V., Polizos G., Randall C. A., Manias E.: Polyethylene nanocomposite dielectrics: Implications of nanofiller orientation on high field properties and energy storage. Journal of Applied Physic, 109, 074113/1-074113/11 (2011).

DOI: $10.1063 / 1.3569696$

[17] Tomer V., Polizos G., Manias E., Randall C. A.: Epoxy-based nanocomposites for electrical energy storage. I: Effects of montmorillonite and barium titanate nanofillers. Journal of Applied Physic, 108, 074116/1-074116/14 (2010).

DOI: $10.1063 / 1.3487275$

[18] Koo J. H.: Polymer nanocomposites: Processing, characterization, and applications. McGraw-Hill, New York (2006).

[19] Finnigan B., Martin D., Halley P., Truss R., Campbell K.: Morphology and properties of thermoplastic polyurethane nanocomposites incorporating hydrophilic layered silicates. Polymer, 45, 2249-2260 (2004).

DOI: 10.1016/j.polymer.2004.01.049

[20] Kim J-Y., Jung W-C., Park K-Y., Suh K-D.: Synthesis of $\mathrm{Na}^{+}$-montmorillonite/amphiphilic polyurethane nanocomposite via bulk and coalescence emulsion polymerization. Journal of Applied Polymer Science, 89, 3130-3136 (2003).

DOI: $10.1002 / a p p .12506$

[21] Janik J.: Effect of multiple processing on the properties of polypropylene nanocomposite (in Polish). Przemysł Chemiczny, 12, 1694-1696 (2010).

[22] Xiong J., Zheng Z., Jiang H., Ye S., Wang X.: Reinforcement of polyurethane composites with an organically modified montmorillonite. Composites Part A: Applied Science and Manufacturing, 38, 132-137 (2007). DOI: $10.1016 /$ j.compositesa.2006.01.014

[23] Tien Y. I., Wei K. H.: Hydrogen bonding and mechanical properties in segmented montmorillonite/polyurethane nanocomposites of different hard segment ratios. Polymer, 42, 3213-3221 (2001). DOI: $10.1016 / \mathrm{S} 0032-3861(00) 00729-1$
[24] Chen-Yang Y. W., Lee Y. K., Chen Y. T., Wu J. C.: High improvement in the properties of exfoliated PU/clay nanocomposites by the alternative swelling process. Polymer, 48, 2969-2979 (2007).

DOI: $10.1016 /$ j.polymer.2007.03.024

[25] Zhang X., Xu R., Wu Z., Zhou C.: The synthesis and characterization of polyurethane/clay nanocomposites. Polymer International, 52, 790-794 (2003).

DOI: $10.1002 /$ pi.1152

[26] Stankowski M., Kropidłowska A., Gazda M., Haponiuk J. T.: Properties of polyamide 6 and thermoplastic polyurethane blends containing modified montmorillonites. Journal of Thermal Analysis and Calorimetry, 94, 817-823 (2007). DOI: $10.1007 / \mathrm{s} 10973-007-8886-\mathrm{X}$

[27] Subramani S., Choi S-W., Lee J-Y., Kim H. J.: Aqueous dispersion of novel silylated (polyurethane-acrylic hybrid/clay) nanocomposite. Polymer, 48, 4691-4703 (2007).

DOI: $10.1016 /$ j.polymer.2007.06.023

[28] Cao X., Lee L. J., Widya T., Macosko C.: Polyurethane/clay nanocomposites foams: Processing, structure and properties. Polymer, 46, 775-783 (2005). DOI: $10.1016 /$ j.polymer.2004.11.028

[29] Pegoretti A., Dorigato A., Brugnara M., Penati A.: Contact angle measurements as a tool to investigate the filler-matrix interactions in polyurethane-clay nanocomposites from blocked prepolymer. European Polymer Journal, 44, 1662-1672 (2008). DOI: $10.1016 /$ j.eurpolymj.2008.04.011

[30] Jang E. S., Khan S. B., Seo J., Nam Y. H., Choi W. J., Akhtar K., Han H.: Synthesis and characterization of novel UV-curable polyurethane-clay nanohybrid: Influence of organically modified layered silicates on the properties of polyurethane. Progress in Organic Coatings, 77, 36-42 (2011).

DOI: $10.1016 /$ j.porgcoat.2010.12.007

[31] Nigmatullin R., Gao F., Konovalova V.: Polymer-layered silicate nanocomposites in the design of antimicrobial materials. Journal of Materials Science, 43, 5728-5733 (2008).

DOI: $10.1007 / \mathrm{s} 10853-008-2879-4$

[32] Khan S. B., Rahman M. M., Jang E. S., Akhtar K., Han H.: Special susceptive aqueous ammonia chemi-sensor: Extended applications of novel UV-curable polyurethane-clay nanohybrid. Talanta, 84, 1005-1010 (2011). DOI: 10.1016/j.talanta.2011.02.036

[33] Cervantes-Uc J. M., Moo Espinosa J. I., CauichRodríguez J. V., Ávila-Ortega A., Vázquez-Torres H., Marcos-Fernández A., San Román J.: TGA/FTIR studies of segmented aliphatic polyurethanes and their nanocomposites prepared with commercial montmorillonites. Polymer Degradation and Stability, 94, 1666-1677 (2009).

DOI: 10.1016/j.polymdegradstab.2009.06.022 